\title{
Characterization of Fly and Bottom Ashes Mixtures Treated using Sodium Lauryl Sulphate and Polyvinyl Alcohol
}

\author{
C.G. Robert ${ }^{1}$, A. Ayob ${ }^{1 *}$, M.F. Muhammad Zaki ${ }^{1}$, M.E. Razali ${ }^{1}$, E.V. Lew ${ }^{1}$, and P.Y. Hong ${ }^{1}$ \\ ${ }^{1}$ School of Environmental Engineering, Universiti Malaysia Perlis, 02600 Arau, Perlis, Malaysia
}

\begin{abstract}
Malaysia promotes coal as an option for solid fuel in electric power generation. Demanding of electricity needs, therefore, has led to increase the coal consumption and thus producing more coal waste products. The disposal of coal waste ashes has been a main concern to power generation station due to the need of disposal sites and operational costs. This study investigates the composition of fly ash (FA) and bottom ash (BA) mixtures with difference component percentage treated with sodium lauryl sulphate (SLS) and polyvinyl alcohol (PVA) at 1.5 and 2.5 $\mathrm{wt} \%$ solutions and examined in terms of specific gravity, $\mathrm{pH}$, maximum dry density properties, and its surface morphology. Although the chemical composition of the SLS and PVA treated fly and bottom ashes studied in this current work is not altered extensively, significant changes could be observed in its physicochemical properties. Chemically treated fly and bottom ashes mixtures with SLS and PVA at $1.5 \mathrm{wt} \%$ solution exhibited specific gravity of 1.97 to 2.92 and high $\mathrm{pH}$ values within range of 9.28 to 10.52. The mixture of $\mathrm{BA}: \mathrm{FA}=0: 1$ ratio depicting high maximum dry density of 1.35 to $1.56 \mathrm{~g} / \mathrm{cm}^{3}$ in both SLS and PVA solutions at 1.5 and 2.5 $w t \%$. Scanning electron microscopy image shows distinct surface morphologies of SLS-treated fly and bottom ashes mixture that the particles are packed closely, strongly bonded similar to popcorn shape due to the effect of active silanol groups acted on coal ashes surface with the presence of Al-O/Si-O/other oxides. These findings suggest that higher level of chemical interaction between the fly and bottom ashes particles, significantly enhances pozzolanic reactions such as shear strength, plasticity, cementing properties, and thus other engineering properties.
\end{abstract}

\section{Introduction}

Coal power plant which generates electricity consumed coal and producing residuals which are fly ash (FA) and bottom ash (BA). Approximately the by-products ratio of coal combustion is $80 \%$ fly ash and $20 \%$ bottom ash [1]. It is estimated both chemically toxic ashes produced as much as 100 million tons in US in the year 1999 [2]. These most complex and abundant of anthropogenic materials, if not properly disposed of, can lead water and soil pollution, disrupt ecological cycles and pose environmental hazards [3].

\footnotetext{
* Corresponding author: afizah@unimap.edu.my
} 
Fly ash is mostly light, fine particle, spherical in shape and grey while bottom ash is heavy, coarse particles, angular and blackish. A dark grey to black colour is typically indicated to elevate unburned carbon content [4]. Fly ash is most often used term to define fine fly ash, particles of which are captured via flue gas and collected by electrostatic of mechanical precipitation. Bottom ash refers to the ash that falls down through the airflow to the bottom of the boiler and is mechanically separated [3]. However, the chemical constituents of both two materials are very similar, with the major difference in their particle shape and size [5].

Engineers been have trying to reuse these by-products in construction includes as road base construction, soil amendment, and apply as a filler in polymer; solving the waste management problem and reducing construction cost by using recycle material. In 2001, researchers suggested that fly ash could increase the strength and durability of concrete [6]. Both fly and bottom ashes have been used in wastewater treatment system as reducer of heavy metals from water by absorption mechanism [7]. In many cases, fly ash alone cannot be used effectively which therefore binding materials or admixtures can be added such as organic polymer, or lime [5]. The use of polymeric materials in settling soil improvement is growing daily, for example application of aqueous polymer modification on soil-polymer interaction by Naeini et al. (2013) [8] and Ates (2013) [9].

However, among the various uses of fly ash, its bulk utilization is feasible only in geotechnical engineering application. The best usage could be as an embankment and road construction. One of the important perimeter in geotechnical is density. Density affect the strength, stability and permeability of a substance to bear load. Previous studies have been conducted in which the characteristics of soil with fly ash mixes were determined in the laboratory. Sahu (2001) [10], stated that maximum dry density decreased with the increase in fly ash proportion and there was hardly any effect on optimum moisture content, as the specific gravity of fly ash was relatively lower than that of soils as well as it counterpart, bottom ash. Additionally, increasing lime content in stabilization of fly ash-soil mixtures, will significantly decrease the maximum dry density of soil-lime mixes, and lowered the optimum moisture content [11]. Santos et al. (2011) [12] suggested that fly ash-soil mixtures exhibits relatively well defined moisture density relationship, varying with mixture ratios. The dry unit weight of fly ash-soil mixtures was lower than those of typically compacted soils. This research study the characterization of fly and bottom ashes mixture treated using sodium lauryl sulphate (SLS) and polyvinyl alcohol (PVA) in regards to its physico-chemical properties, maximum dry density and its surface morphology.

\section{Material and methods}

Fly ash and bottom ash used for this research has been acquired from Jana Manjung coal power plant in Perak, Malaysia. SLS and PVA of molecular weight $\sim 20,000$ and $\sim 288$, respectively, that fully hydrolyzed were purchased from Sigma Adrich and used as recieved. The mix proportions in percentage of weight were denoted as 1:0, 3:2, 2:3 and 0:1 for BA:FA ratios, were examined for its grain size particle and specific gravity. The SLS and PVA were dissolved in distilled water at $80^{\circ} \mathrm{C}$ to prepare about 1.5 and $2.5 \mathrm{wt} \%$ solution. $\mathrm{pH}$ values were determined after stirring the samples on the mixed solutions for 15 mins to allow the $\mathrm{pH}$ of the slurry to stabilize.

These coal ashes treated with the SLS or PVA solutions were then placed in a stirrer with continuous shaking at 130 revolutions per minute. Thereafter, the 20 individual mixtures tested at various water content of $8 \%, 12 \%, 16 \%, 20 \%$, and $24 \%$ were filtered and washed numerous times with distilled water, poured into square molds of $100 \mathrm{~mm} \times 100$ $\mathrm{mm} \times 100 \mathrm{~mm}$, and dried for 2 days at ambient curing, before undergo Proctor compaction 
test adhering to ASTM D689 standard [13]. The morphological characterization of 28 days curing specimen was studied through scanning electron microscope (JEOL JSM 6460 LA).

\section{Results and discussions}

\subsection{Grain size distribution}

Fig. 1 shows the grain size distributions of the fly and bottom ashes from Jana Manjung, and their varying BA:FA ratio of mixtures. Generally, the fly ash was well graded, ranging from mostly silt to fine sand size, in a range between $0.075 \mathrm{~mm}$ to $0.2 \mathrm{~mm}$. The small size of spherical fly ash particles gives to a better packing of aggregate materials, which decrease porosity, and therefore significantly increase the compressibility and workability of fly-bottom ashes mixtures for further engineering application. While for the bottom ash, its sizes occurred in a range between $2.0 \mathrm{~mm}$ to $4.75 \mathrm{~mm}$ that mostly coarse sand to gravel size.

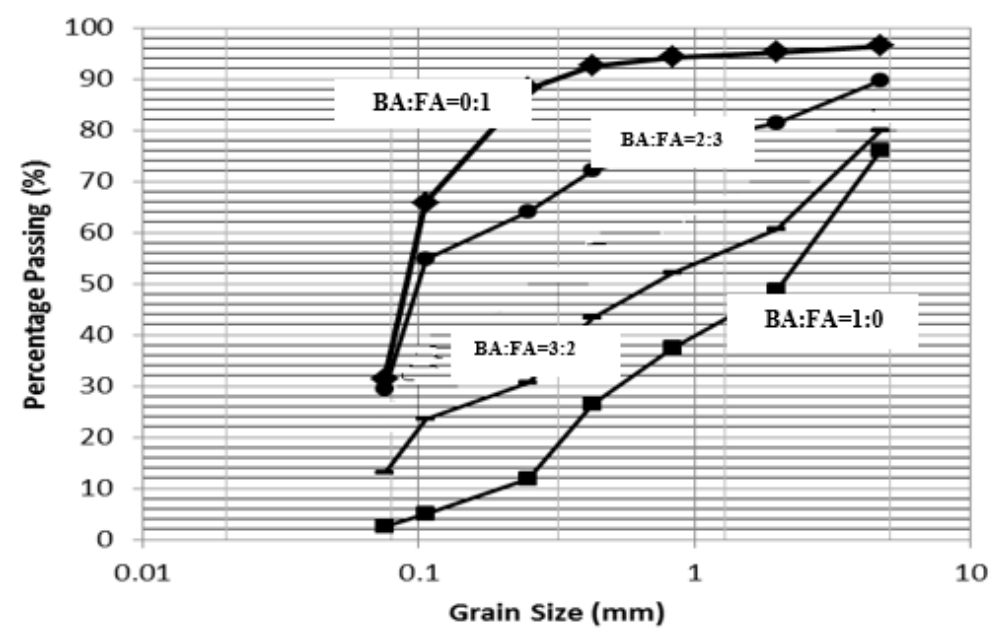

Fig. 1. Grain size distribution of untreated Jana Manjung coal ashes.

\subsection{Specific gravity and $\mathrm{pH}$ values}

Table 1 shows the range of specific gravity values for fly and bottom ashes mixtures recorded between 1.97 to 2.86 and 2.15 to 2.5 treated with $1.5 \mathrm{wt} \%$ solution of SLS and PVA, respectively.

Table 1. Specific gravity and $\mathrm{pH}$ vale of BA:FA mixtures with $1.5 \mathrm{wt} \%$ solution of SLS and PVA.

\begin{tabular}{lcccccccc}
\hline \multirow{3}{*}{ Parameter } & \multicolumn{7}{c}{ Treated with 1.5\% SLS } & \multicolumn{7}{c}{ Treated with 1.5\% PVA } \\
\cline { 2 - 9 } & $\mathbf{1 : 0}$ & $\mathbf{3 : 2}$ & $\mathbf{2 : 3}$ & $\mathbf{0 : 1}$ & $\mathbf{1 : 0}$ & $\mathbf{3 : 2}$ & $\mathbf{2 : 3}$ & $\mathbf{0 : 1}$ \\
\hline Specific gravity & 2.92 & 2.00 & 2.86 & 1.97 & 2.50 & 2.48 & 2.38 & 2.15 \\
pH value & 9.37 & 9.28 & 9.41 & 9.56 & 10.58 & 10.35 & 10.52 & 9.50 \\
\hline
\end{tabular}

The difference in the range of these values could be due to two factors; (i) the chemical composition and (ii) presence of hollow fly ash particles or either bottom ash particles with their porous or vesicular structure. In both treatment methods, bottom ash mixtures 
(BA:FA=1:0), depicted higher specific gravity values of 2.92 and 2.50 , than that of fly ash alone (BA:FA= 0:1; 1.97 and 2.15), this could be due to the higher contents of iron oxide and the larger and irregular bottom ash particles in the first mixture.

In the coal ash constituent, fly ashes contain of amorphous ferro-alumino silicate, in which these aluminum, iron, and manganese oxides will absorb the trace element [5]. Therefore, during the $\mathrm{pH}$ testing, the solubility of these oxides determined the release of elements to the solution. Both treated mixtures with SLS and PVA at $1.5 \mathrm{wt} \%$ are alkaline, with the ranging $\mathrm{pH}$ value from 9.28 to 10.52 (Table 1 ). The $\mathrm{pH}$ value of ash-water system determine mainly on the calcium/sulphur molar ratio in ash, yet other minor alkalis or alkaline earth cations do give to the balance.

\subsection{Effect of SLS and PVA treatment to maximum dry density value of fly and bottom ash mixtures}

All compaction data have been plotted into dry density against moisture content as shown in Fig. 2.

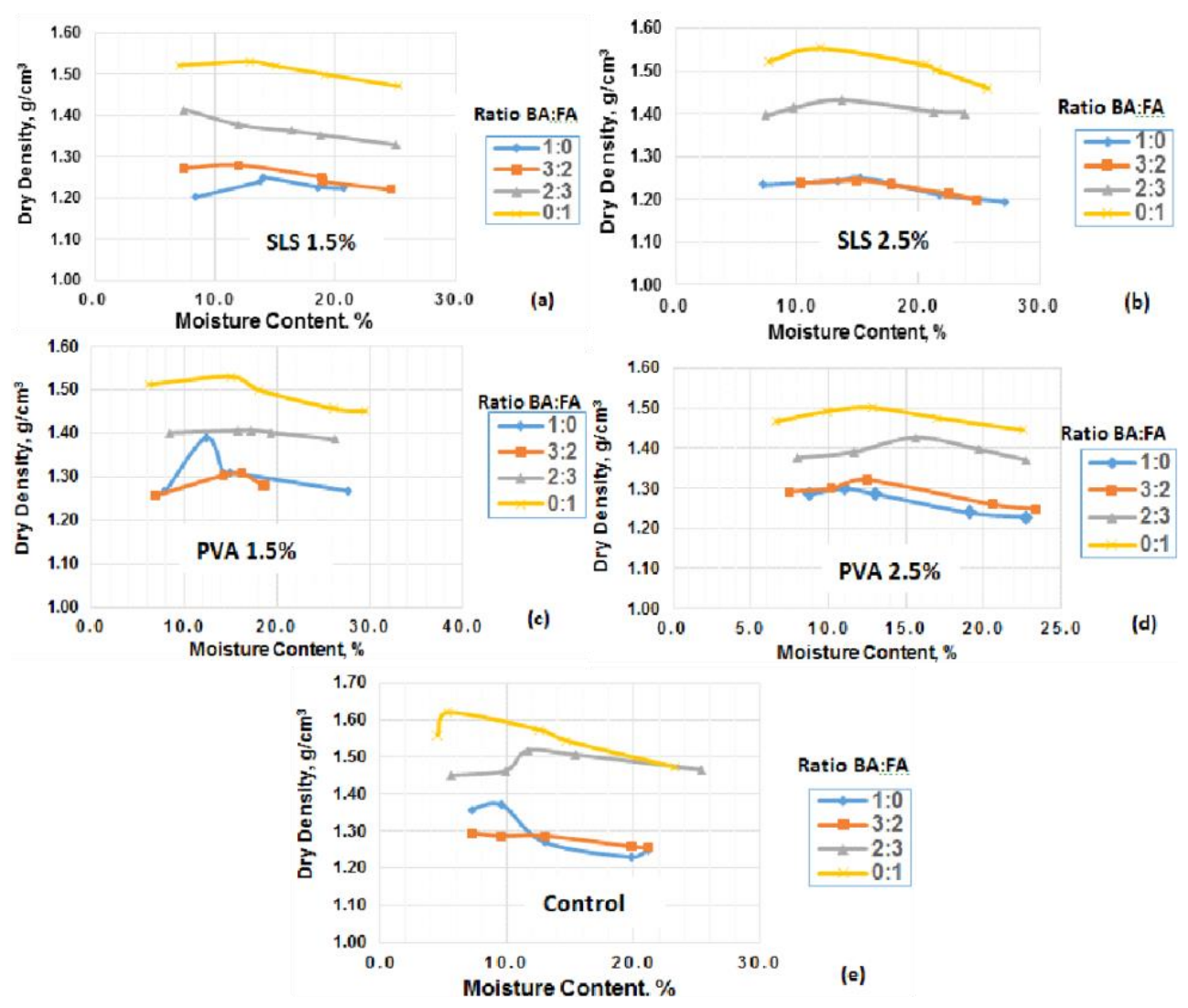

Fig. 2. Maximum dry density value for specimen treated with SLS solution at (a) $1.5 \%$ (b) $2.5 \%$, and PVA solution at (c) $1.5 \%$, (d) $2.5 \%$, and untreated (control) specimen for the mixing BA:FA ratio of $1: 0,3: 2,2: 3$, and $0: 1$.

All test samples were showing curve similar to the non-cohesion soil. Fly ash alone $(\mathrm{BA}: \mathrm{FA}=0: 1)$ showing high maximum dry density of 1.35 to $1.56 \mathrm{~g} / \mathrm{cm}^{3}$ in both $\mathrm{SLS}$ and 
PVA solutions of 1.5 and $2.5 \mathrm{wt} \%$, while bottom ash (BA:FA=1:0) depicting the lowest values $\left(1.19\right.$ to $\left.1.30 \mathrm{~g} / \mathrm{cm}^{3}\right)$. These trends continue as less bottom ash (BA:FA = 2:3) were added into the mixture, the maximum dry density decreases. The gap between highest and lowest dry density for each mixes is rather equivalent for both treatment methods of SLS and PVA. As the fly ash content decreases (BA:FA=3:2) the maximum dry density is decreasing and the moisture content values recorded $18.5 \%$ to $24 \%$.

The inclusion of low weight fly ash and irregular coarser bottom ash in the SLS or PVA chemical solution can make the mixed samples comparatively coarser and decrease the overall weight. These decreases resulted from the flocculation and agglomeration of ash particles in present of sufficient chemical solution leading to increase in voids and thus, decrease in dry densities (BA:FA=3:2; Fig. 2b, 2c). At the same time, the reason for the increasing moisture content could be due to the affinity of the soil-fly ash mixed samples for more water to complete the cation exchange reaction and with the applied of compaction effort the voids are occupied by more water (BA:FA=0:1; moisture content $=29.5 \%$; Fig. 2c). In addition, for the control specimen (Fig. 2e), some weak and large cenosphere fly ash particles $(\mathrm{BA}: \mathrm{FA}=0.1)$ are crushed into finer particles during the compaction, thus lowering air content, because the fines fill up the voids between the matrix, and significantly contributing to higher maximum dry density $\left(1.48\right.$ to $\left.1.63 \mathrm{~g} / \mathrm{cm}^{3}\right)$ and decrease in moisture content values (5\% to $22 \%)$. This finding is consistent to Pal and Gosh (2010) [14], in their study of influence physical properties of class F fly ash.

In comparison between the effect of SLS and PVA chemical solutions to the maximum dry density of fly and bottom ashes mixture, qualitative analysis has been conducted (Table 2). Calculated standard deviation of $5.91 \%$ to $9.43 \%$ and $2.03 \%$ to $4.45 \%$, respectively for varying maxing ratios of BA:FA and manipulating the percentage of solution at 1.5 and 2.5 $\mathrm{wt} \%$. The standard deviation values indicate low significance effect of two difference methods of chemical treatment (SLS vs. PVA; 1.5 and $2.5 \mathrm{wt} \%$ ) for the maximum dry density values.

Table 2. Standard deviation calculated from maximum dry density values for each mixes of diference BA:FA ratios treated by using SLS and PVA solution.

\begin{tabular}{|c|c|c|c|c|}
\hline \multirow[b]{2}{*}{ Samples } & \multicolumn{4}{|c|}{ Calculated standard deviation } \\
\hline & $\begin{array}{c}\text { BA:FA } \\
(1: 0)\end{array}$ & $\begin{array}{c}\text { BA:FA } \\
(3: 2)\end{array}$ & $\begin{array}{c}\text { BA:FA } \\
(2: 3)\end{array}$ & $\begin{array}{c}\text { BA:FA } \\
(0: 1)\end{array}$ \\
\hline Untreated & 1.37 & 1.30 & 1.52 & 1.62 \\
\hline Treated with $1.5 \%$ SLS & 1.25 & 1.28 & 1.41 & 1.53 \\
\hline Treated with $2.5 \%$ SLS & 1.25 & 1.25 & 1.43 & 1.55 \\
\hline Treated with $1.5 \%$ PVA & 1.39 & 1.25 & 1.41 & 1.53 \\
\hline Treated with $2.5 \%$ PVA & 1.30 & 1.32 & 1.43 & 1.50 \\
\hline
\end{tabular}

\subsection{Morphological characterization of fly and bottom ashes mixtures treated with SLS and PVA solution}

SEM images show the surface morphologies of untreated and treated fly bottom ashes mixture in $1.5 \mathrm{wt} \%$ solution of SLS and PVA after 28 days of curing. SEM images shows that the untreated botttom ash of BA:FA $=0: 1$ has rough, irregular and complex in shape particles (Fig. 3a), while the mixture with higher fly as (BA:FA = 2:3, Fig. 3b), exhibited smooth surface and good sphericity, eventhough some particles were observed agglomerated into a large particle tightly attached to each other.

For the treated samples, a distinct morphological difference were observed in both mixtures, (Fig. 2c, 2d), where the fly and bottom ashes particles are packed more closely and strongly bonded similar to popcorn shape due to the effect of SLS by the presence of active silanol groups on the coal ashes surfaces (Al-O/Si $-\mathrm{O} /$ other oxides), that cause 
strong filler-filler interactions leading to more adhesive specimen (BA:FA = 3:2, Fig. 2c). Therefore this observation suggests higher level of chemical interaction between the coal ash particles, which significantly enhances pozzonalic reaction, increase its cementing properties, and thus its engineering properties.

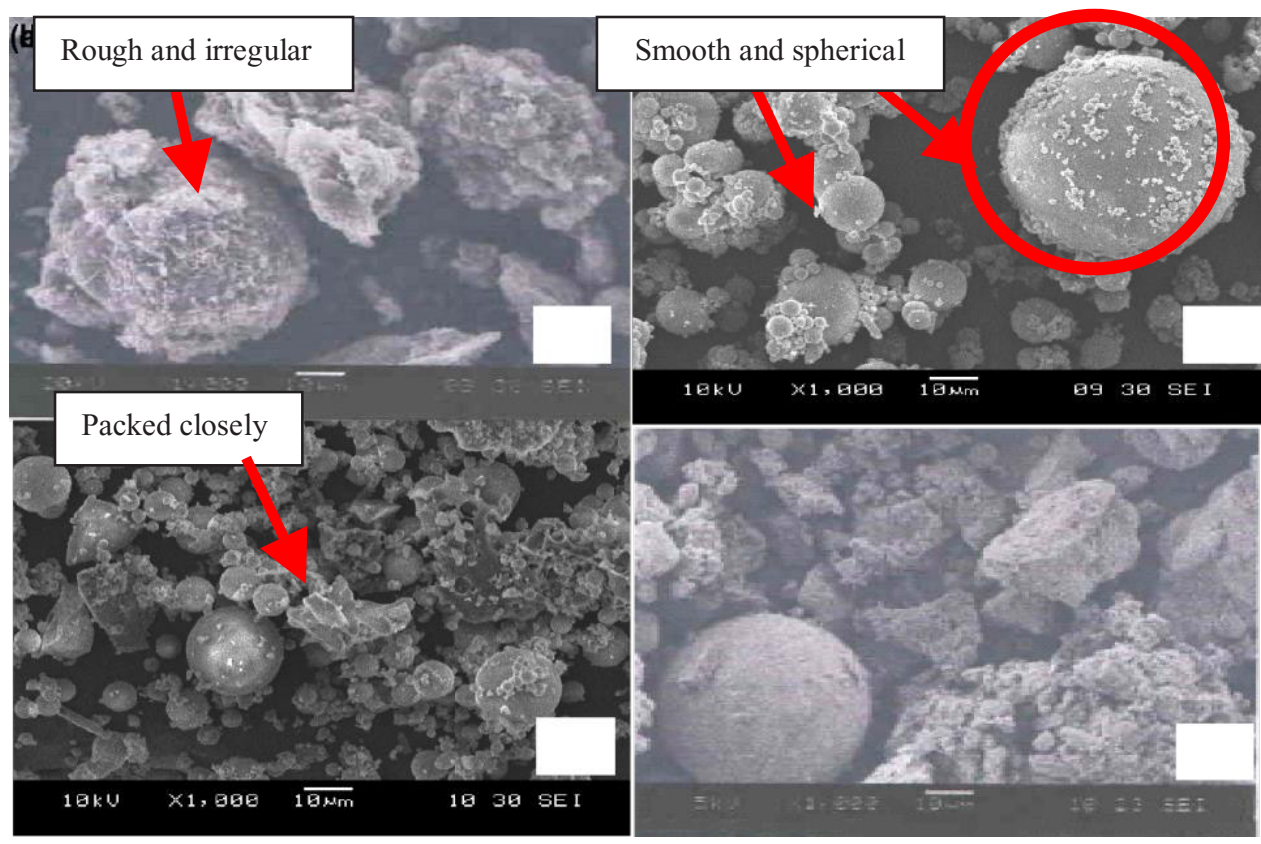

Fig. 3. SEM surface morphology of untreated (a) $B A: F A=1: 0$, (b) $B A: F A=2: 3$, treated speciemen with $1.5 \%$ wt. solution of (c) SLS for $\mathrm{BA}: \mathrm{FA}=3: 2$, and (d) BA:FA $=2: 3$ for 28 curing days.

\section{Conclusions}

Grain size particles of fly ash is fine and nearly spherical, mostly within the range of 0.01 to $2.0 \mathrm{~mm}$, the bottom ash $(0.08$ to $5.0 \mathrm{~mm})$ is consists of coarse-grained solid particles. The specific gravity and $\mathrm{pH}$ recorded for fly ash and bottom ash treated mixtures with $1.5 \%$ wt. solution of SLS and PVA are within the range of 1.97 to 2.92, and 9.28 to 10.58 , respectively. No specific trend of relationship between grain-size distribution and specific gravity. Treated fly ash alone (BA:FA= 0:1) in SLS and PVA of $1.5 \%$ to $2.5 \%$ wt. solution contribute to higher maximum dry densities of 1.35 to $1.56 \mathrm{~g} / \mathrm{cm}^{3}$. However, as the mixture ratio become $\mathrm{BA}: \mathrm{FA}=3: 2$, total comparative weight decrease, resulted from particles flocculation and agglomeration in the SLS and PVA solution, that increase voids, and consequently lower the maximum dry density. In comparison of two difference chemical solutions of SLS and PVA, no significance difference has been observed in regards to maximum dry density for treated fly ash and bottom ash mixtures. The chemically treated fly ash and bottom ash sample with SLS shows a distinct morphological surface difference as the particles are agglomerated, packed more closely, and strongly bonded due to the effect of active silanol groups, which enhances the pozzolanic chemical reactions and the engineering properties such as the plasicity and shear strength thus leading possibility for futher geotechnical applications.

This research is fully supported by Research Acculturation Grant Scheme (RAGS No: 9018-00078). The authors fully acknowledged Ministry of Higher Education (MOHE) and Universiti Malaysia 
Perlis (UniMAP) for the approved fund which makes this important research viable and effective. Thank you to the Jana Manjung Power Plant, Perak for their approval and assistance of getting the sample from the site.

\section{References}

1. A. Ayob, M.Z.A.M. Zahid, M.F.M. Zaki, S.H.A. Hamid, M.A.M. Yussuf, A.N.M. Yunus, Adv. Environ. Biol. 8(22), 25-29, (2014)

2. E.A. Okunade, Mod. App. Sci. 4(12), (2010)

3. Z.T. Yao, X.S. Ji, P.K. Sarker, J.H. Tang, L.Q. Ge, M.S. Xia, Y.Q. Xi, Earth Sci. Rev. 141, 105-121, (2015)

4. D. Shaunik, S.S. Gupta, Int. J. Basis App. Agr. Res. 12(1), (2104)

5. C.G. Robert, A. Ayob, M.F.M. Zaki, M.Z.A.M. Zahid, L. Ee Von, J. Adv. Res. Mat. Sci. 10(1), 12-25, (2015)

6. I. Siddique, M.I. Khan, Supplementry Cementing Materials, Springer Science \& Business Media, London, (2001)

7. A.R. Awang, A. Marto, A.M. Makhtar, EJGE 16, 1515-1531, (2011)

8. S.A. Naeini, B. Naderinia, E. Izadi, KSCE J. Civil Eng. 6 (16), 943-949, (2012)

9. A. Ates, Int. Journal Polymer Sci. 356214, (2013)

10. B.K. Sahu. In Symposium on Int. Ash Utilization. Kentucky, USA, Centre of App. Energy Res. (2001)

11. A. Kumar, B.S. Walia, A. Bajaj, J. Mat. Civil Eng. 19(3), 242-248, (2007)

12. F. Santos, L. Li, Y. Li, F. Amini, In Proceedings og World of Coal Ash Conference, Denver, USA, May 9-12 (2011)

13. ASTM Standard C698, Standard Test Methods for Laboratory Compaction Characteristics of Soil Using Standard Effort, ASTM International, West Conshohocken, PA, 2015. www.astm.org. (2012)

14. S.K. Pal, A. Gosh, Indian Geo. Conference, Dec. (2010) 